\title{
IRANIAN GARDEN'S ARCHITECTURAL DESIGNING: COLLOCATION OF VORONOI AND FRACTAL ALGORITHMS IN THE CONTEXT OF NATURAL BACKGROUND
}

\author{
Somayyeh Omranifar ${ }^{\star 凶}$, Shabnam Namdar², Nader ghaemi33, Yaser Narimanpour Maleki4 \\ ${ }^{1}$ PhD student of Architecture, Architecture Department, Islamic Azad University, Tabriz Branch, Tabriz, Iran \\ ${ }^{2}$ Assistant professor, Architecture Department, Islamic Azad University, Tabriz Branch, Tabriz, Iran \\ 3 Architecture Department, Islamic Azad University, Tabriz Branch, Tabriz, Iran \\ 4 Department of Architecture, Islamic Azad University, Mashad Branch, Mashad, Iran
}

\section{Research Article \\ PII: S238315531800004-7 \\ Received: 10 Sep. 2018 \\ Revised: 05 Dec. 2018 \\ Published: 15 Dec. 2018}

Corresponding author's e-mail: Somayeh.omranifar@gmail.com

\begin{abstract}
In the present article, the collocation of the Fractal Geometries and Voronoi Algorithm has been proved in line with the designing of garden's digital architecture and it was made clear that the designing of the ancient four-segment gardens is considerably matching with the contemporary architecture which has come about subject to the effect of computers and software. The present study is a qualitative research of descriptive-analytical type and it has been conducted with a glance at the history of Iranian gardens' designs and their delineated geometrical analyses concerning the structural philosophy of Voronoi and Fractal algorithms. The primary goal of the researcher is showcasing the timelessness in the designing of the Iranian garden so as to prove that the prior designing has been in accordance with the novel patterns of the contemporary architecture and it can get the paradise manifested like before in a corner of the earthy ground in today's machining world. It can be stated as a part of the obtained results that the idea of exhibiting water in the garden and the system of water transmission to the most distant spots in the garden tries depicting the ancient imaginations of the previous architects about Voronoi algorithm considering the use of the shortest path which is a perpendicular line drawn towards a dot on a straight line. Moreover, the use of four-segment garden's basic module and its division in an internally descending manner displays Fractal geometry in each of Voronoi levels of the garden's plots.
\end{abstract}

\section{KEYWORDS}

Iranian garden, Geometry, Voronoi algorithm, Fractal, Water

\section{INTRODUCTION}

The thing that is currently seen in the Iranian cities as buildings and urban spaces and elements has not been able to crystalize the fruitful background of Iranian architecture and garden-building and it is, instead, depicting a sort of distinct identity lack and self-alienation. Lack of paying attention to the social and cultural values and hasty movement towards modernity without the real perception of what is being constructed and processed have led to visual, cultural, social and identity unrest in the level of Iranian cities and architecture [1].

Iranian garden has always endeavored since long ago to stay in accord with a philosophical and contextual-functional concept and it has been embodied as one of the specifications of Iranian architecture. Considerable differences were brought about in the context of Iranian architecture and garden-building with the beginning of the foreign advisors' trip to Iran from Safavid Era and the blending of the Iranian architecture and decorations with what has been offered as art and technique to
Iranians. The architectural context and gardenbuilding methods lost their performance and beauty of their geometrical ground and their connection rings were broken in such a way that the performance occasionally led to the discarding of beauty and the paying of attention to the visual beauties resulted sometimes in the creation of insensible cases in the gardens' grounds. Therefore, the researchers have been coerced to subtly contemplate about the functional and visual designing of the Iranian gardens so as to identify the meanings latent in them beyond the plan of Iranian four-segment garden thereby to figure out the missing rings of the function and beauty; it is by the perception of the concepts existent behind the functional and visual designing of the gardens that solutions can be found for logical attachment to the contemporary mankind's psychological needs. In the present study, the author proves the basics existent in fractal geometry and digital Voronoi algorithms within the former geometrical context of the Iranian garden and shows that the nature's flexible spirit has been portrayed in the meaning-oriented designs by 
the imaginative ancient architect in such a way that it has been able to absorb the psychological states and satisfy the needs of the today's mankind in the area of the contemporary naturalism.

The researcher seminally deals with the theoretical foundations and the concepts usually encountered regarding the Iranian gardens; then, the references of the Iranian gardens' patters are extracted. Next and after deeply studying the structural philosophy and theoretical foundations of Voronoi and fractal algorithms, the feasibility of adjusting the current theoretical foundations and their structural philosophy to the geometrical plan of the Iranian garden has been analyzed. All the analyses have been discussed geometrically and, considering the functionalist and human-oriented grounds of the contemporary architecture and garden-building, the existing functional factor has been displayed as a connecting ring.

The main question of the present study is that what is the primary functional factor that can, as a connecting ring of the garden's humanism and naturalism concepts, make the geometrical design of the garden approach the timeless concept?

How are such digital and naturalist geometries like Voronoi and fractal algorithms matched on the grounds of the Iranian garden? The author tries answering the above-posited questions in five chapters, namely the Iranian garden and formation process, Voronoi and fractal algorithms, Iranian garden and collocation of water-transmission function with Voronoi algorithm and Iranian garden and fractal geometry in the geometry of the plots.

\section{Iranian Garden and Formation Process:}

The concept of "garden architecture" reflects a "sense of place"; garden is defined as a space that has the perfect and utmost reflection of the world in it. This concept that fosters order and coordination might be expressed more tangibly by means of numbers, geometry, color and matter [2]. Based on the studies that have been carried out on the reference patterns of the Iranian garden, the primitive sample of the archetypes has been applied as the common contact surface between the patterns of Iranian gardens and it has also been crystalized in the Iranian carpets; it depicts a square-shaped area of a relatively vast land which is surrounded inside walls. The surface area of this land has been divided by two axes (two water streams) perpendicular to and intersecting one another with the main stream eventually pouring into four ditches and with trees finally surrounding the square. The most major building of the garden falls in the intersection point [3].

\section{System of Geometrical Structure:}

The geometrical structure of the Iranian garden is shaped in two substantial forms with one of the indices of its geometrical structure being the relationship between the interior and exterior spaces [4]: one is the creation of three stretches (in three axes) in parallel and along with the garden and the other is the consideration of two primary perpendicular axes and then dividing of the garden into squares that per se have their own regular geometrical divisions (Figure 1). In Iranian garden, special attention was paid to the geometrical shapes and square that showcased a simple and clear-cut distance between the garden's components enjoyed a particular importance [5].
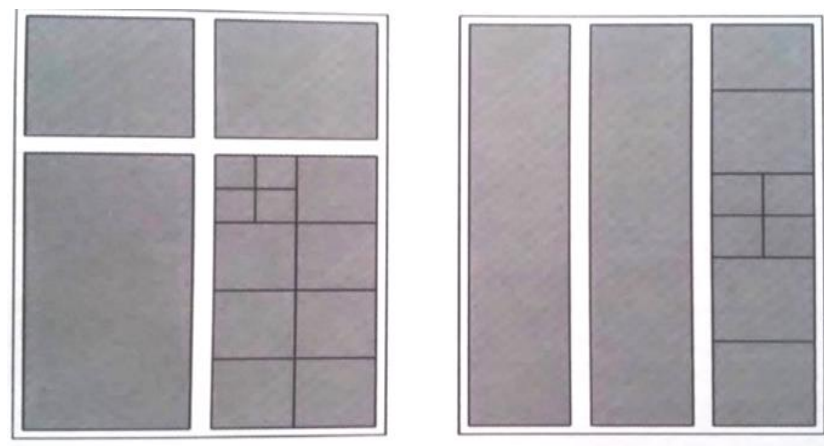

Figure 1. Geometrical structure of the garden [3].

\section{Voronoi Algorithm:}

Voronoi algorithm is a geometrical algorithm. This algorithm receives a series of points as its input. These points can be selected randomly and/or be certain points on a plane [6]. In this type of algorithm, the input points lead to the production of a series of regions on the plane and, problemspecifically, give the closest answers with the highest likelihood for the calculation of the region of a point by considering all the line segments between the given point and the other points. Then, the bisectors of these line segments are drawn and the regional bisectors are created around the given point [7]. In this case, the algorithm juxtaposes the given regions without overlapping. It has been recently proved that many of the structures follow this algorithm in nature (Figure 2), especially the micro-structures of the nature wherein the Voronoi schemes are abundantly found [6]. 


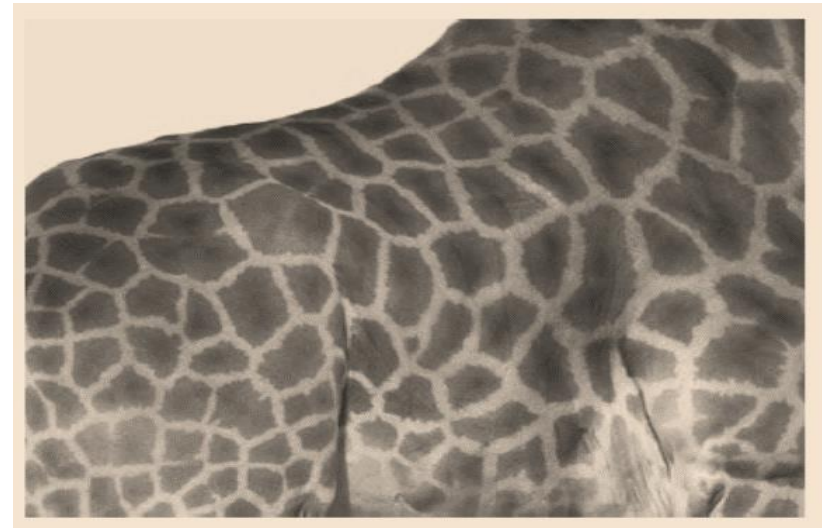

Figure 2. Voronoi algorithm in nature [8].

There are also more complex forms of Voronoi algorithms the regions of which are made by soft curves in lieu of the broken lines. Furthermore, there are also $3 \mathrm{D}$ images of this algorithm that receive the initial points in a given space and gives the area zoning by dividing of the spaces (Figure 3). In architecture, various Voronoi algorithms have been widely applied [8].

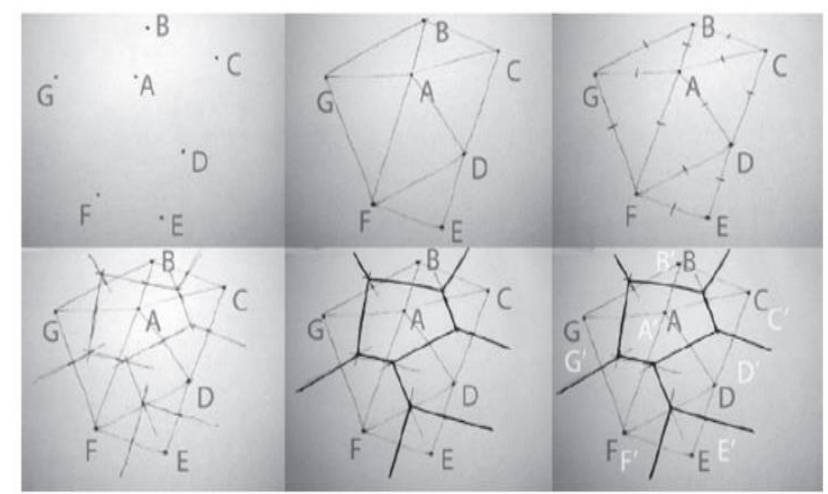

Figure 3. The structure of Voronoi algorithm [8].

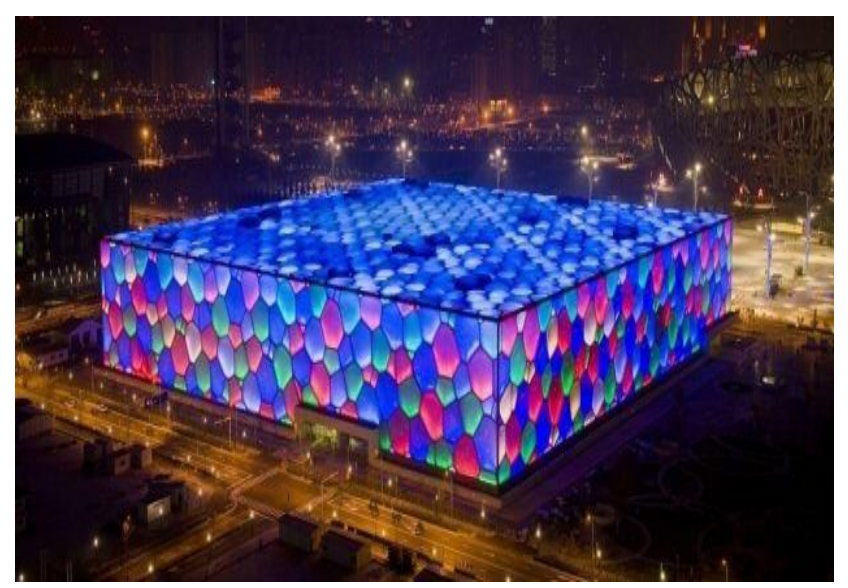

Figure 4. The structure of Voronoi algorithm (http://arktourism.ir)
Figure 4 illustrates the unique and well-known example of Voronoi algorithm has been displayed in the cubic water building (the name that has been given to the stadium of water sports in Pecan, China). Besides having a lot of advantages in terms of the architectural form and creation of modern and innovative structures, this building is completely environment-friendly and it is enumerated, in other words, as a green and environment-compliant structure. The primary idea of this complex's designing has been the formation of a cube that has been brought to existence from the joining of waterfilled bubbles and it is completely transparent [8].

\section{Fractal}

Fractal is a geometrical shape that is created with the repetition of a simple logic in a recursive manner. In a normal manner, the shape obtained from the fractals can be divided into several parts each of which resembling the overall shape. The other interpretation existent about the fractals is that they have indefinite components and/or they possess similar structures making them look identical in the various magnifications. The term "fractal" was first used by Mandelbert in 1975. It is derived from the Latin root "fractus" meaning broken [9].

In the process of a fractal's production, there are at least two primary shapes: one basic and one generative. In every stage of the repetition, the generative shape is placed in the position of every one of the basic shape's fundamental segment or line segment. From the theoretical perspectives, this repetition can be continued endlessly. The algorithm used for producing the fractal shapes is a basic process the job of which is placing one shape between two points. This process includes the size change, rotation and displacement of the generative shape for taking a position between the two presumed points or two ends of a line segment. Amongst the simplest types of the fractals are the Sierpinski triangle (Figure 5) and fractal cube [6].

In the traditional Iranian architecture, as well, the fractal pattern can be seen in Karbandi [geometrical and mathematical planning], Yazdibandi [roof covering] and ornamental corbel vaults. In these patterns, the basic module is iterated with a special order to create an integrated whole. The fractal pattern has also been inserted in the architectural form. This pattern is occasionally symbolic and it is sometimes inserted in the wefts and warps of the architectural function (Figure 6). 


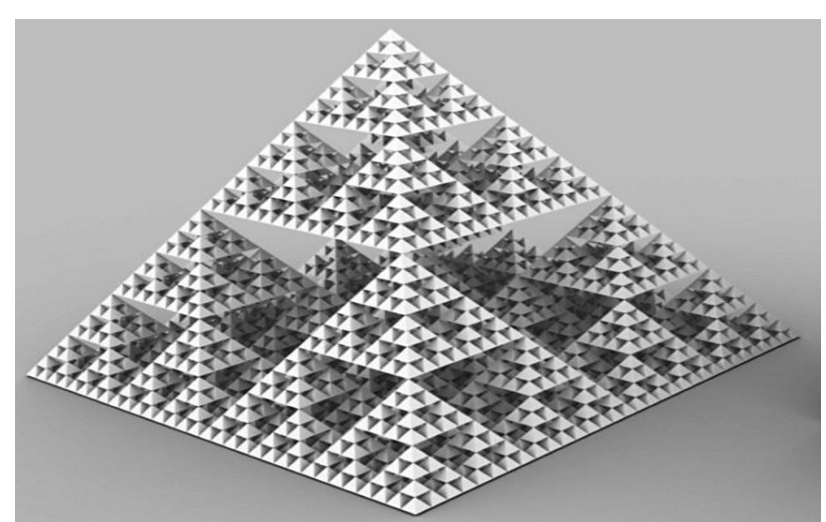

Figure 5. Sierpinski fractal triangle (http://spnueng.blogfa.com)

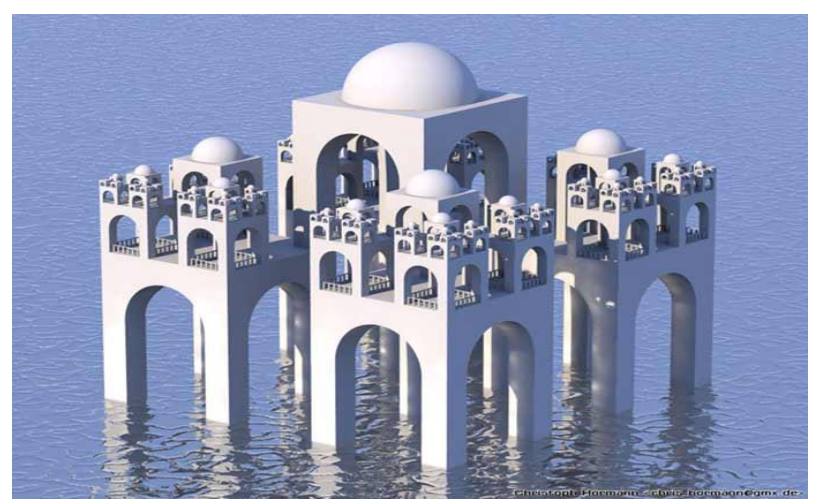

Figure 6. Symbolic fractal architecture (http://honartech.ir/product)

\section{Iranian Garden and Collocation of Water- Transmission Function with Voronoi Algorithm:}

Iranian garden is the geometrical embodiment of paradise in the context of a scorching desert with an extreme inclination towards water exhibition in every corner being one of its primary specifications [9]. That is because is considered as the symbol of dynamicity and life in the desert. The most original solution for showcasing it and taking a more appropriate advantage thereof is its management in the middle of the garden in such a way that the water starts flowing from the longest edge of the garden and proves presence in the entire garden while performing its duty of satiation. Concentration on the soil's natural slope has been the easiest solution in the previous gardens.

According to figure 7 , points $\mathrm{A}$ and $\mathrm{C}$ are considered as the input points of Voronoi algorithm. Considering the use of square geometry for the easy recognition of the distances in the garden, point $B$ is the place where the pond should be placed and its stretching gives the points $\mathrm{E}$ and $\mathrm{D}$. this way, the preliminary pattern of the four-segment gardens is formed by dividing the land into four areas with two input points, an operator point and two result points.
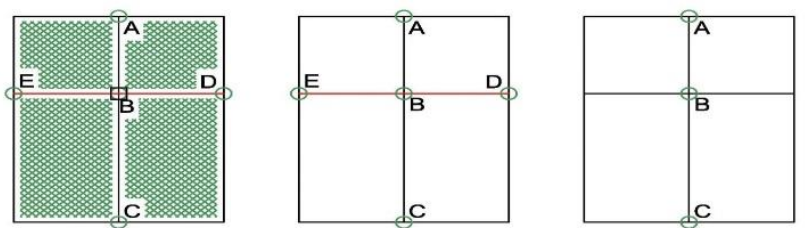

Figure 7. Functional formation of the basic foursegment garden (source: the author)

In order to accomplish the objective of water display and water transmission to all the garden's spots, preparatory measures should be taken so that the water can be transmitted to all the various spots of the garden in respect to the land's slope. In line with this goal, some other points have been considered as the input points of Voronoi algorithm and, considering the water-transmission function and water display, the shortest paths have been offered according to the philosophy of Voronoi algorithm in two states of the land slope.

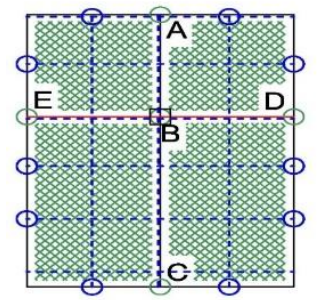

Case 1

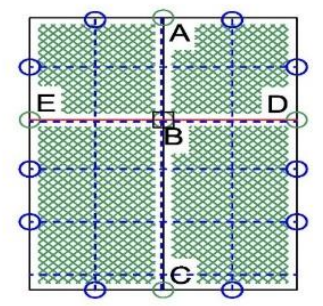

Case 2
Figure 8. Formation of Voronoi algorithm in the garden's geometry (Source: the author)

As it is seen in figure 8, the first case pertains to gardens that have been positioned in respect to the land's natural slope in an ascending or descending form. In this type of gardens, water starts flowing from its source and is brought from a garden to another [5]. Water enters through the point $\mathrm{A}$ and reaches the point $B$ from which it is distributed along the operator ED axis in the lower half of the garden. In order to transmit water to the upper plots, the upper axis includes water inlet as the secondary operator axis and water is subsequently distributed in the upper plots.

The second case shows the method of water transmission in the gardens that are usually irrigated by wells' water. In this type of gardens, the intersection of the two primary axes is considered as the water inflowing point and the land's slope is assumed to be towards the walls on the four sides of the garden [5]. In this state, only one operator axis is 
considered for the garden. The gardens in the deserts usually make use of this method. The water line axis shows the water-transmission system.

Considering the Voronoi algorithm and according to the goal of transmitting water to the most distant spots in the garden, certain points are considered on the peripheral walls and vertical lines are presumed from the water's primary stream according to the mathematical principle recommending the selection of the shortest perpendicular route from the point onto the water stream following which the Iranian garden's watertransmission network/system is formed within the format of four-segment garden. It is by locating certain points on the wall that squares and rectangles are geometrically formed in respect to the amount of water required to be transmitted to the plots.

Considering the Voronoi algorithm, the thing that is effective in the shape obtained from the algorithm is the number of the points to which water should be transmitted in respect to water power and land's shape. If a garden is square in shape with large dimensions and the soil slope is not so much steep and/or if water is withdrawn from wells for satiating the garden, smaller Voronoi areas will be attained. However, if the surface area is considered similar to the previous example with a rectangular geometry, the resulting shape will be different and follows the land's slope following which the number of the plots will be reduced.

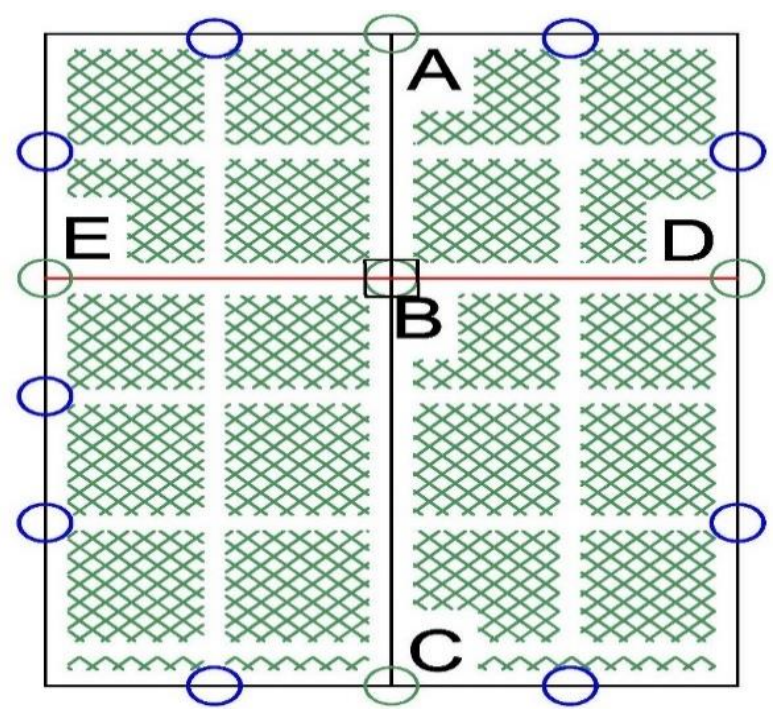

Figure 9. Voronoi algorithm based on the basic four-segment pattern (Source: the author)

Figure 9 exhibit the Voronoi algorithm in collocation with the water-transmission function in the garden and proves that the original pattern of the Iranian garden is adjusted to the contemporary digital architectural patterns drawn on Voronoi algorithm.

The stretch of the traditional market's body within the city limits of Tabriz and the prominent historical buildings like Dar Al-Fonun School, Darb Baghmishe, Haramkhaneh Complex, municipality building and so forth as well as the valuable business edifices like the large market of artefacts and the large bazar of Tabriz's leather have caused this region to be transformed into one of the tourism spots of the city. The adjacency of the unique tourism potentials to Tabriz County's trade pole, organized within the limits of Jomhouri Street, has caused the vehicles' access to the aforesaid centers to encounter considerable limitations and factors like excessive congestion of the region, lack of cargotransportation infrastructures and blending of the industrial and tourism uses and heavy traffic on Shahid Madani Street and adjacent streets have caused the creation of problems in terms of urban tourism in the foresaid region.

\section{Iranian Garden and Fractal in the Plots' Geometry:}

The most original factor in the formation of fractal geometry is the basic module and the scattering path and method of this module in the general format. Considering the functional system of the square-shaped geometry of the garden, the upper section is defined as the basic module in the garden and the entirety of the garden's surface area is covered through the arrangement of this module based on Voronoi algorithm and the primary geometry of the plots is formed in a descending (downsizing) trend in the module-dividing state. Figure 10 illustrates the plots' fractal process in Iranian gardens.

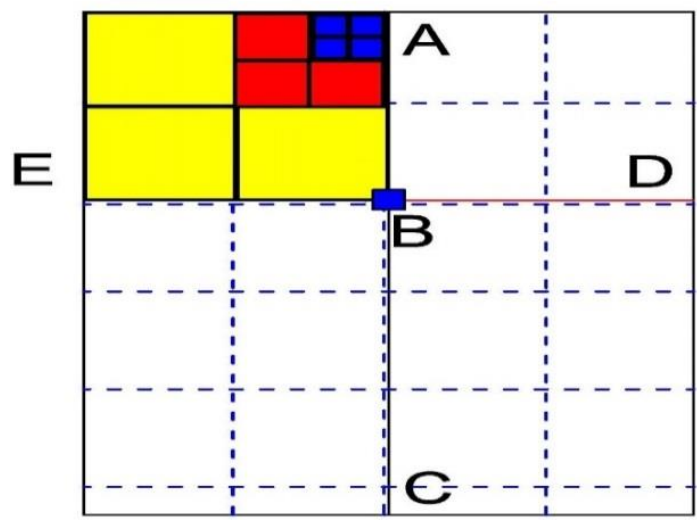

Figure 10. Formation of the fractal pattern (source: the author) 
According to the pictorial information and their analysis, it was made clear that the four-segment garden's geometry that has been applied as the primary geometry in the architectural designing of the Iranian gardens follows and is matched with the patterns produced in Voronoi and fractal algorithms. In addition, the water-transmission function and the idea of water display is the ring connecting the garden's geometry to Voronoi and fractal algorithms. The former architect and garden-builder followed the nature to create a beautiful paradise in the heart of a scorching desert and getting the imaginary nature manifested in the grounds of the available land. It is worth mentioning that the naturalism ground in Voronoi and fractal algorithms as well as the geometrical designing of the gardens have created the aforesaid harmony and match.

\section{CONCLUSION}

In the present study and through more subtle study of the geometrical and functional systems of the gardens, the geometrical adjustability of the garden's architecture with the structural and philosophical patterns of Voronoi and fractal algorithms was proved in respect to the contemporary basics of the digital architecture and it was made clear that the idea of water display as a social value and power in the low-water regions as well as the carriage of water to the most distant spots of the plots is the ring connecting the concept of the garden and the digital algorithms to the garden's geometry and architecture. Depending on the system of water division in respect to the land's slope and water transmission to the plots in the shortest possible path which is the vertical line obtained from a given point on the destination line, the four-segment garden pattern is implemented in the entirety of the garden which is reflective of the structural pattern of Voronoi algorithm in the architectural designing of the garden. Additionally, the fractal geometry in the garden's architecture is showcased by the repetition of the basic module of the preliminary four-segment garden's pattern that has been formed in the upper section of the garden in terms of elevation and implemented in the adjacency of the water inlet with an internal-descending multiplication in the whole four-segment garden on the ground surface.

\section{Competing interests}

The authors declare that there is no competing interest.

\section{REFERENCES}

[1] Noghrehkar A, Hamzehnejad M and Ranjbar Kermani AM (2012). An introduction to the Islamic identity in architecture and urban engineering", Tehran, Payame-Simagaran, 487.

[2] Ardalan N, Bakhtiar L. (2011). Sense of unity, the role of tradition in Iranian architecture. Tehran, Scientific Research Institute of Royal Architecture. 2011: 40. Google Scholar

[3] Shahcheraghi A (2011). Recreating the Iranian Garden Architecture System, PhD Thesis in Architecture, Islamic Azad University, Science and Research Branch.

[4] Hekmati J. (2007). Engineering of the green spaces, designing of parks and villas. Tehran, Sepehr, 16.

[5] Farahani LM, Motamed B, Jamei E. Persian gardens: Meanings, symbolism, and design. Landscape online. 2016 Jan 31;46:1-9. Google Scholar ; https://doi.org/10.3097/LO.201646

[6] Spiller N. (2008). Digital architecture now: A global survey of emerging talent. Thames \& Hudson. Google Scholar; http://gala.gre.ac.uk/id/eprint/9351

[7] Abolhasani, S M and Razazi, M R (2007). New algorithm for determining the status of point in convex polygons. $13^{\text {th }}$ National Conference held by Iran's association of computer, Kish, Persian Guld, Iran, 1-4.

[8] Uddin, M. S. (1999). Digital architecture. Google Scholar

[9] Mostaghni AR and Alimoradi M (2016). Exploring the application of the fractal and the nature's geometry in the parametric architecture with an investigation of the interior decorations of the dome in Sheikh Lotfollah Mosque. Seasonal Journal of Architecture and Urban Engineering. (16): 103-121.

[10] http://honartech.ir/product.

[11] http://spnueng.blogfa.com

[12] http://arktourism.ir

[13] Bhatti SA and Firkins JT. (2008). See at http://www.forbesindia.com/printcontent/41571 